\title{
Trade Imbalance of Shanghai Information Industry based on Ternary Marginal Model
}

\author{
J.W. ZHANG, J.H. DUAN, W.Y. HUANG, L.J. LI \\ Department of Customs Management, Shanghai Customs College, Shanghai, China
}

\begin{abstract}
In this paper, on the basis of international trade theory, the "Ternary Marginal Model" is used to conduct structural effects of trade imbalance from the perspective of trade security. Our research can be divided into following three parts: the overview of the current situation of SHII, the introduction of "Ternary Marginal Model" and the analysis of trade imbalances by using this model.

KEYWORD: Shanghai Information Industry (SHII); Trade Imbalance; Ternary Marginal Model
\end{abstract}

\section{INTRODUCTION}

Last several decades have witnessed the rapid development of SHII, the international competitiveness of which has been greatly improved. With the growing import and export trade volume, information industry is increasingly becoming a vital manifestation of China's national economic development. But meanwhile, the import and export trade imbalances have been around for a long time, which should be seriously considered.

Many scholars at home and abroad have studied information industry in the past two decades. For instance, Junhua Yu and Hongtao Xie (2006) made a thorough research and analysis on the status of China's electronic information industry and policy adjustments of foreign trade. Other relevant articles include Ward, Ellen P.(2002), Yunting Dong(2002), Chunfang Zheng(2008), Zongyao Wu(2012) and etc. They followed various methodologies to study the development of information industry as well as modeled trade data. And the results of their analysis are of great significance and value for our paper.

Nevertheless, although information industry trade theory has gradually matured, there are still few people studying the Trade Imbalance of SHII. So we tried to use the "Ternary Marginal Model" to analyze this issue, hoping to find some valuable inner link.

\section{MODEL ANALYSIS}

In trade activities, the total value of the product has been broken down into three dimensions: type, quantity and price. Therefore, Trade data can also be divided into range of trading products (breadth), trading volume and trading prices of products in the import and export trade to conduct the structural effects. In different ways of trading, the relative weight of these three areas and the growth rate is not the same [1]. Learning from the Ternary Marginal Model pioneered by Professor Bing Shi (2010), trade imbalance has also been divided into three parts: breadth imbalance, quantity imbalance and price imbalance. Nonparametric techniques should be used to study SHII from safety perspective [2].

The definition of trade imbalance is that there exists difference between import and export value, which can be represented by the ratio of export and import value amount.

$$
r=\frac{V E X_{i j}}{V I M_{i j}}=\frac{\sum_{k \in E X} e x_{i j k}}{\sum_{k \in I M} i m_{i j k}}
$$

Where: $r$ represents the ratio of exports and imports, namely the degree of trade imbalances,

If $r>1$, said the trade surplus, $r<1$, said the trade deficit, $r=1$ represents a balance;

$V E X_{i j}$ represents export Value, VIM $i j$ represents import Value;

$i, j, k$, respectively represents exporters, importers and products.

EX, IM denote the collection of export and import products, its intersection is EXIM.

\section{POSITIVE ANALYSIS}

This chapter, we studied the structural effects of 
Shanghai's information industry trade imbalance using ternary marginal model through relevant data, and evaluate the status of the information industrial security of Shanghai on this basis.

The SHII in this article refers to the following three categories of information products (with coded information): computer communications and integrated manufacturing technology (84), electrical and electronic products (85) and electronics (90).

According to the Fig. 1, we found out that the degree of trade imbalance of SHII shows a volatility rising trend year by year. The trade imbalance is characterized by surplus since 2004. By 2013, the imbalance degree is 1.813 , which is almost three times as much as the year of 2002. Being influenced by the global economic crisis, degrees of 2008 and 2009 reached a small peak. And as shown in Fig. 2, in addition to chapter 90 , chapter 84 and 85 have a growing trade surplus from year 2004. These two Figures reflect the development of SHII as well as the serious trade imbalance of its industry.

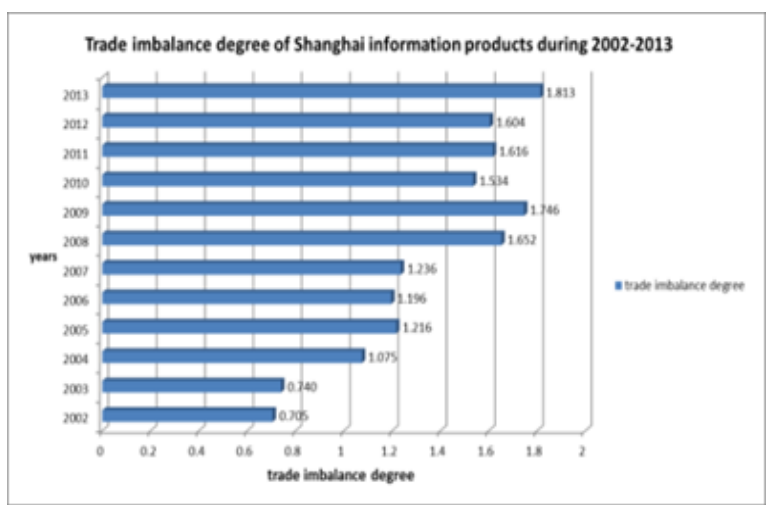

Fig. 1: Trade imbalance degree of Shanghai information products during 2002-2013 Data source: Shanghai customs

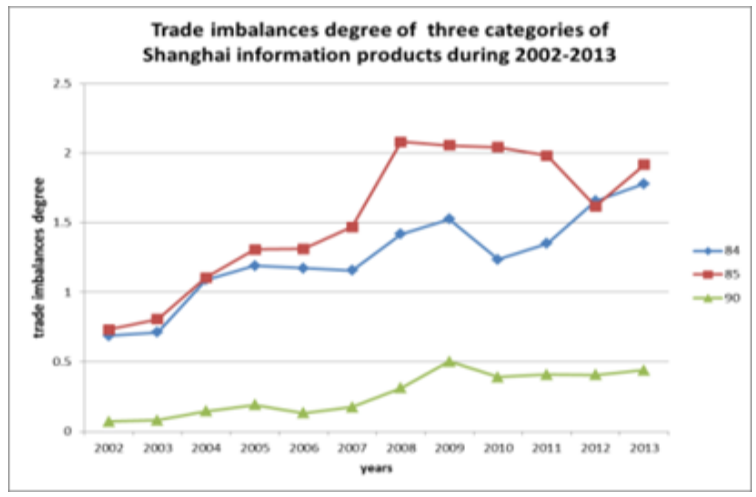

Fig. 2: Trade imbalances degree of three categories of Shanghai information products during 2002-2013 Data source: Shanghai customs

\subsection{Positive analysis of breadth imbalance}

Data from Shanghai customs tells us that there is an upward trend in export breadth till 2013, but the import breadth had a sharp decline in 2012, which led to a rapid rise in trade imbalance degree. The reason of the increasing breadth imbalance, on the one hand, is that the development of SHII improves the recognition of the international markets. On the other hand, the demand for information products abroad has fallen in the past two years. The widening gap of import and export varieties reveals an unreasonable proportion, which reflects the characteristic of the Shanghai information industry development to some extent [3].

The width of trade shows the level of the commodity classification of a country's industry, the larger the number, the greater the trade volume. Fig.3 shows that the export of Shanghai information products to the US continues to be in deficit in breadth. And Fig. 4 gives us a developing tendency of the contribution degree, the numerical value kept positive and increased year by year after 2004, which means that trade breadth has a significant contribution to the information industry trade between Shanghai and the US.

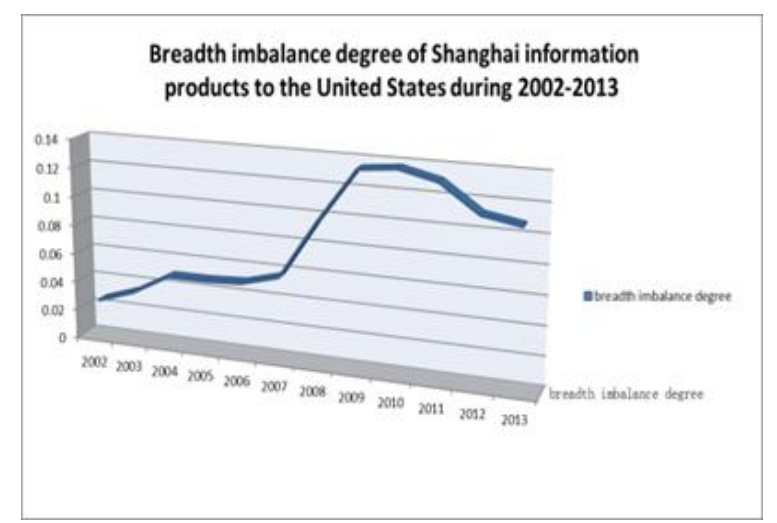

Fig. 3: Breadth imbalance degree of Shanghai information products to the United States during 2002-2012 Data source: Shanghai customs

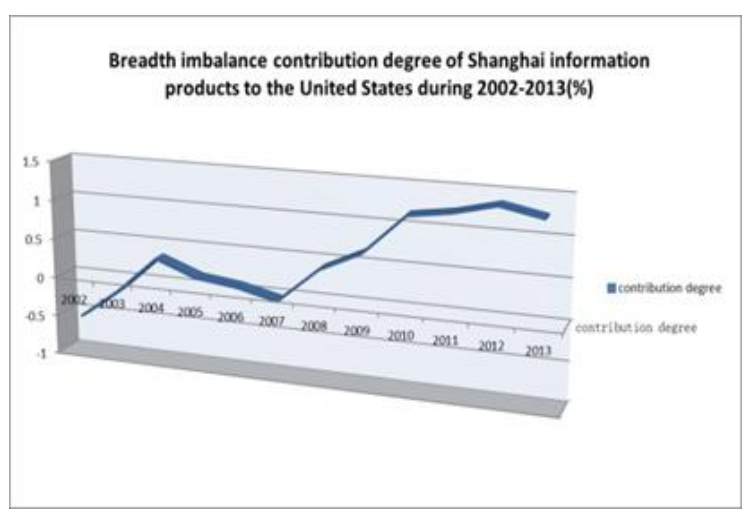

Fig. 4: Breadth imbalance contribution degree of Shanghai information products to the United States during 2002-2013 Data source: Shanghai customs

\subsection{Positive analysis of number imbalance}

As is shown in figure 5 and figure 6 , influenced by the American subprime mortgage crisis in 2008, the international market development was slow. SHII imports dropped year by year in 2008-2012. However, after countries around the world gradually recovered from the crisis, Shanghai information industry exports had a continuous declination during 2009- 
2013.The reasons of the drop can be concluded as follows: global economic downturn as a result of the financial crisis, negative consumer confidence and the competitive advantage of export-oriented enterprises reduces because of the appreciation of the $\mathrm{RMB}$, which further led to blocked export.

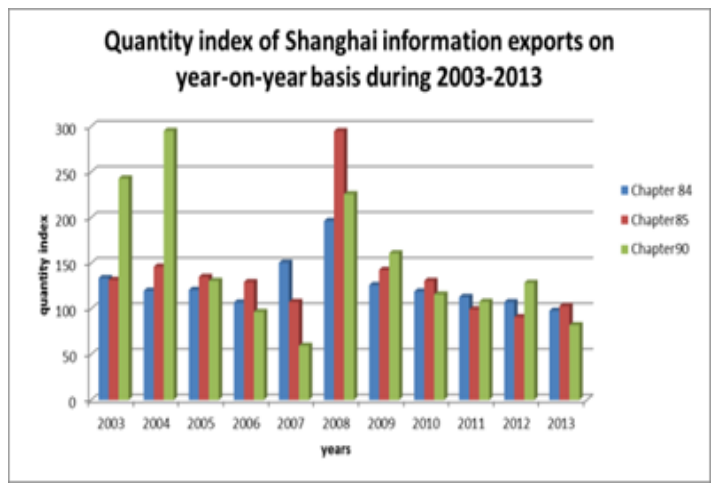

Fig. 5: Quantity index of Shanghai information exports on yearon-year basis during 2003-2013 Data source: Shanghai customs

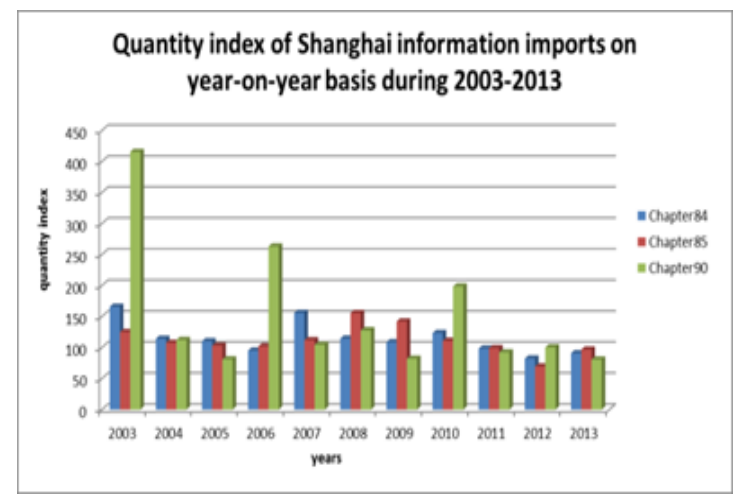

Fig. 6: Quantity index of Shanghai information Imports on year-on-year basis during 2003-2013 Data source: Shanghai customs

Number imbalance reflects the export trade quantity of a country's industry. On the basis of the Shanghai customs import and export data, through calculation, we found that Shanghai information products' export volume to the US has an expand tendency from the Fig. 7, which means Shanghai information industry has a significant number of quantity surplus. However, in the process of development, Shanghai information industry grew more profligate, relying on cheap labor and policy support to expand scale and increase production, rather than through the use of advanced production technology and improve labor productivity to gain higher profits. This volume surplus partly reflects the status of international division of labor and comparative advantage of Shanghai information industry, but this kind of crude growth depending on low cost and increasing consumption of resources is not conducive to the healthy and sustainable development of information industry [4]. What's more, Fig. 8 gives us a clear conclusion that the contribution degree of the number of trade remained above $100 \%$ since 2010 . In general, the rising trend shows that number imbalance has a more and more crucial impact on Shanghai information industry.

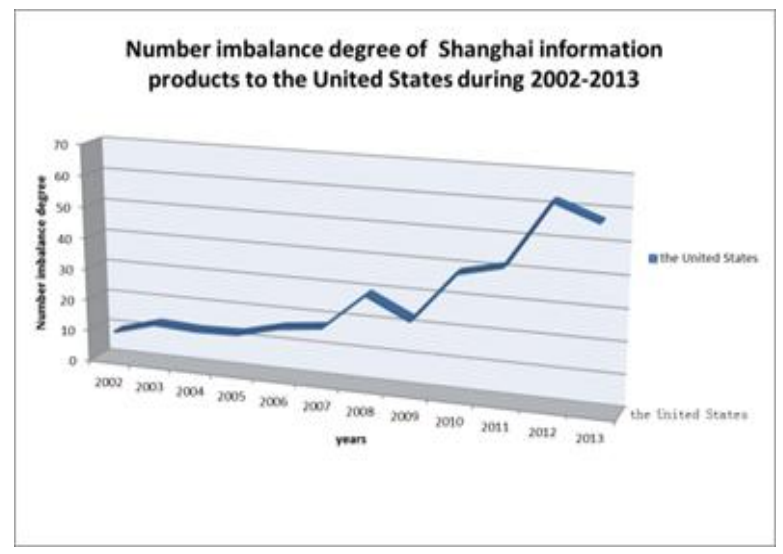

Fig. 7: Number imbalance degree of Shanghai information products to the United States during 2002-2013 Data source: Shanghai customs

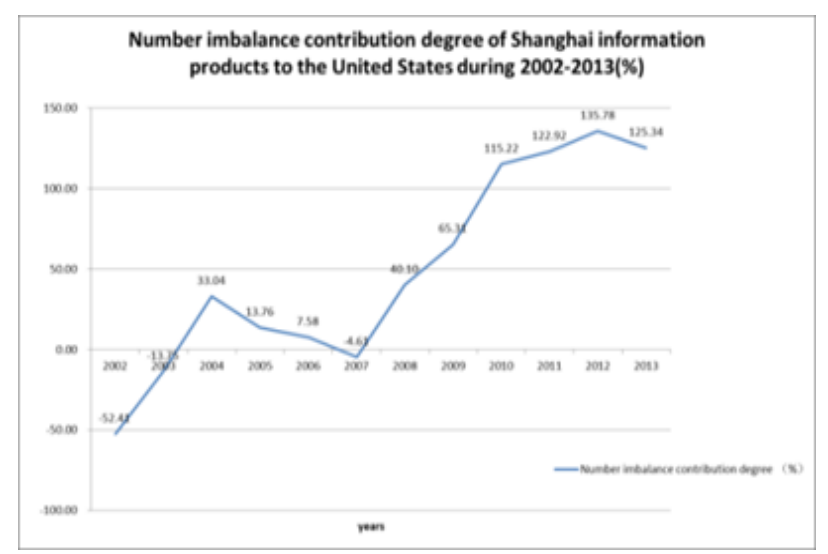

Fig. 8: Number imbalance contribution degree of Shanghai information products to the United States during 2002-2013 Data source: Shanghai customs

\subsection{Positive analysis of price imbalance}

We can see from the Figures that, with a growth trend of fluctuations, the price index of 2003-2013 Shanghai information imports and exports appears to be unstable [5]. In order to realize industry upgrading, methods should be taken to deal with the problems such as integrating industry resources and optimizing the industrial structure.

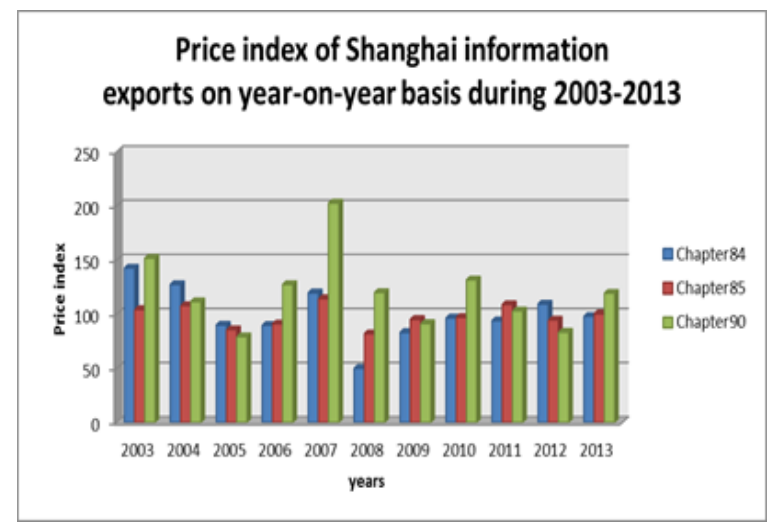

Fig. 9: Price index of Shanghai information exports on year-onyear basis during 2003-2013 Data source: Shanghai customs 


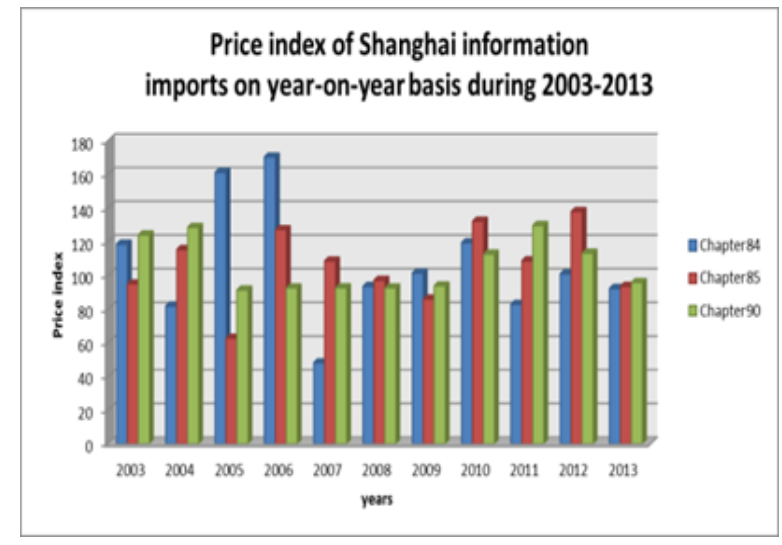

Fig. 10: Price index of Shanghai information imports on yearon-year basis during 2003-2013Data source: Shanghai customs

Price is determined by the value, at the same time influenced by supply and demand. Fig. 11 shows us that Shanghai information exports' price to the US has a long-term deficit. This is mainly decided by the intrinsic value of the products, most of the exports to the US are ordinary and at low price. What's worse, compared with well-known brands of high-priced imports from the US, we give high priority to processing trade, but neglected the brand and core technology. Due to the different locations in the global value chain, this kind of phenomenon is difficult to change in a short period of time. By comprehensively analyzing, price imbalance has a slight contribution to Shanghai information products to the US.

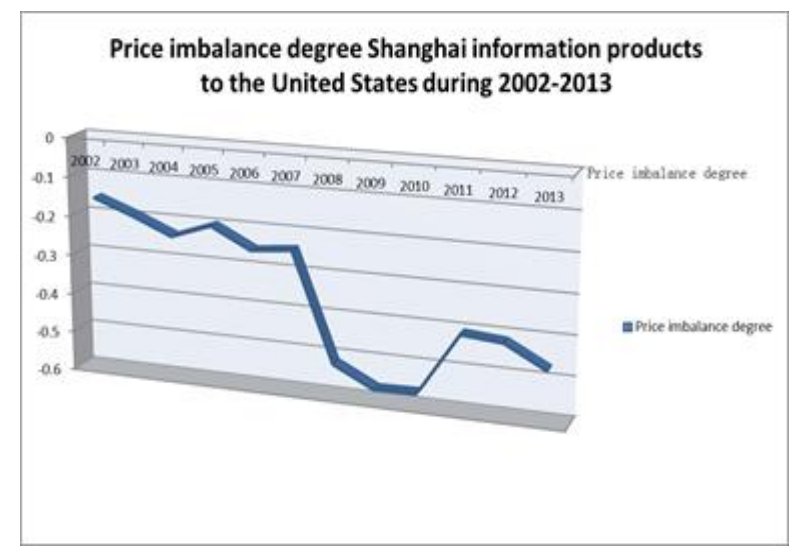

Fig. 11: Price imbalance degree of Shanghai information products to the United States during 2002-2013 Data source: Shanghai customs

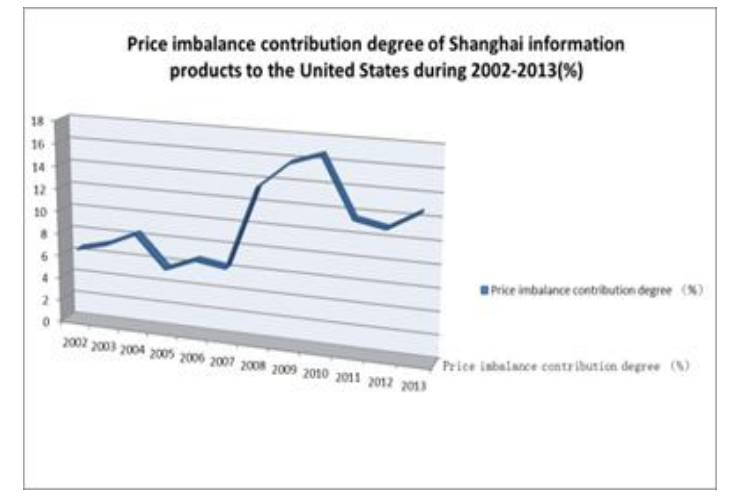

Fig. 12: Price imbalance contribution degree of Shanghai information products to the United States during 2002-2013 Data source: Shanghai customs

\section{CONCLUSIONS}

After the model and positive analysis, we can have a clearer assessment to the trade imbalance of SHII. Results show that: Number imbalance caused the trade imbalances of SHII, the effect of breadth and price of balance are slight. To conclude, the trade surplus is made up with the number of surplus, the breadth and the price deficit, but the contribution of them is different. The number imbalance makes the largest contribution, compare to a smaller contribution of the breadth and price.

\section{ACKNOWLEDGEMENT}

This work was financially supported by the national university students' innovative and entrepreneurial training project (201310274007).

\section{DEADLINE}

The above material should be with the editor before the deadline for submission. Any material received too late will not be published. Send the material by airmail or by courier well packed and in time. Be sure that all pages are included in the parcel.

\section{REFERENCES}

[1] Y.Dong \& S.Chen: China Soft Science, Vol.09 (2002), p. 3-7.

[2] P.Zhao \& H.Sun: Shanghai Economic Forum, 04 (2004), p.24-28.

[3] B.Cao: IT Time Weekly, Vol.12 (2004), p.60-63.

[4] J.Yu \& H.Xie: Practice in Foreign Economic Relations and Trade, Vol.09 (2006), p.5-10.

[5] C.Zheng: Economic Issue, Vol.07 (2008), p.31-35. 